\title{
O DISCURSO TELEVISIVO E O SUJEITO TRANSEXUAL: EFEITOS DE SENTIDOS NA MÍDIA
}

\author{
THE TELEVISION DISCOURSE AND THE TRANSEXUAL SUBJECT: \\ EFFECTS OF SENSE IN THE MEDIA
}

\author{
EL DISCURSO TELEVISIVO Y EL SUJETO TRANSEXUAL: EFECTOS DE \\ SENTIDOS EN LA MEDIA
}

Jaqueline Angelo dos Santos DENARDIN

\section{RESUMO}

Neste trabalho, a partir da perspectiva teórica da Análise de Discurso (PÊCHEUX, 1969, 1975), articulada aos estudos do gênero (BEAUVOIR, 1949; BENTO 2008; BUTLER, 2003) e outros teóricos que possam contribuir com as discussões propostas, pretende-se analisar a série Quem sou eu?, transmitida pelo programa televisivo da Rede Globo de Televisão Fantástico. Realizada em quatro episódios, com circulação em quatro domingos consecutivos, entre os meses de março e abril de 2017, a série abordou o tema da transexualidade e as demandas pertinentes e "inerentes" ao sujeito transexual, tais como: as "escolhas" de quem nasceu no corpo "errado"; a repercussão na vida escolar e acadêmica por ser um sujeito trans; a questão da automedicação e tratamento(s); a cirurgia de transgenitalização e os relacionamentos no "mundo transgênero", tanto em relação às questões de afeto familiar, quanto às questões de desejo sexual. O objetivo principal é analisar quais são os discursos presentes no(s) dizer(es) e como estes se materializam na linguagem como um modo de fazer falar o tema da transexualidade. Este estudo ainda tem como intuito analisar o funcionamento ideológico que permeia as discussões feitas pelo programa televisivo acerca desse tema

- assunto que tem sido pivô de várias discussões na contemporaneidade com repercussão social intensa, o que justifica cientificamente esta pesquisa e a necessidade de abordar a transexualidade no espaço de produção científica, para que não tenha, como dito, somente o que
ABSTRACT

In this work, the theoretical perspective of Discourse Analysis (PÊCHEUX, 1969, 1975), articulated to the studies of the genre (BEAUVOIR, 1949; BENTO 2008; BUTLER 2003) and other theorists who can contribute with the proposed discussions, is intended analyze the series Who am 1?, broadcast on the TV show Globo TV Fantastic TV. The series covered the theme of transsexuality and the pertinent and "inherent" demands of the transsexual subject, such as the "choices" of who was born in the "wrong" body; the repercussion in school and academic life for being a trans subject; the issue of self-medication and treatment ( $s$ ); transgender surgery and relationships in the "transgender world", both in relation to issues of family affection and questions of sexual desire. The main objective is to analyze the discourses present in the statement (s) and how they materialize in language as a way of making the subject of transsexuality speak. This work is also intended to analyze the ideological functioning that permeates the discussions made by the television program about this subject - a subject that has been the pivot of several discussions in contemporary society with intense social repercussion, what scientifically justifies this research and the need to approach transsexuality in the space of scientific production, so that it does not have, as said, only what is produced by common sense, thus enabling an epistemological construction of knowledge and knowledge about transsexuality. Therefore, this work intends to understand how the effects of senses

\section{RESUMEN}

En este trabajo, la perspectiva teórica del Análisis del Discurso (PÊCHEUX, 1969, 1975), articulada a los estudios del género (BEAUVOIR, 1949, BENTO 2008, BUTLER 2003) y otros teóricos que puedan contribuir con las discusiones propuestas, se pretende analizar la ¿Quién soy yo?, transmitida en el programa de TV Globo TV Fantastic TV. La serie abordó el tema de la transexualidad y las exigencias pertinentes $y$ "inherentes" del sujeto transexual, como las "elecciones" de quienes nacieron en el cuerpo "equivocado"; la repercusión en la vida escolar y académica por ser un sujeto trans; la cuestión de la automedicación $y$ el tratamiento ( $s$ ); transgénero, cirugía y relaciones en el "mundo transgénero", tanto en relación a las cuestiones de afecto familiar como a las cuestiones de deseo sexual. El objetivo principal es analizar los discursos presentes en la (s) afirmación (s) y cómo se materializan en el lenguaje como forma de hacer hablar al sujeto de la transexualidad. Se pretende también con este trabajo analizar el funcionamiento ideológico que permea las discusiones del programa televisivo sobre el tema - tema que ha sido el eje de diversas discusiones en la sociedad contemporánea con intensa repercusión social, lo que justifica científicamente esta investigación y la necesidad de abordar la transexualidad en el espacio de la producción científica, de modo que no tiene, como dicho, sólo lo que es producido por el sentido común, posibilitando asi una construcción epistemológica del conocimiento y del conocimiento sobre la transexualidad. Por lo tanto, este trabajo pretende comprender cómo 
é produzido pelo senso comum, possibilitando, assim, uma construção epistemológica do conhecimento e saberes sobre a transexualidade. Portanto, este trabalho tem a intenção de compreender como se sustentam efeitos de sentidos - ditos e não ditos - em dizeres produzidos pelo discurso televisivo de tal programa; ademais, analisou-se como os sujeitos trans se dizem e são ditos nessa série sobre sua transexualidade

PALAVRAS-CHAVE:

Análise de Discurso; Discurso

televisivo; Efeitos de Sentidos; Série

Quem sou eu?; Sujeito Trans.
- said and not said - are sustained in the words produced by the television discourse of such a program; in addition, analyzed how trans subjects are said and are said in this series about their transsexuality.

\section{KEYWORDS:}

Discourse Analysis; Television discourse; Effects of Senses; Series Who am I ?; Subject Trans. los efectos de los sentidos -los dichos y no dichos- se sostienen en las palabras producidas por el discurso televisivo de tal programa; además, analizó cómo los sujetos trans se dicen y se mencionan en esta serie sobre su transexualidad.

\section{PALABRAS-LLAVE:}

Análisis de Discurso; Discurso televisivo, Efectos de Sentidos; ¿Quién soy yo? Sujeto Trans

\section{DIZERES INICIAIS}

Este trabalho busca analisar discursivamente como o tema transexualidade foi abordado na série Quem sou eu?, exibida no programa televisivo Fantástico, de abrangência nacional, transmitido pela Rede Globo de Televisão. O propósito de tal análise emergiu porque, num primeiro momento da série, o sujeito transexual, por vezes, compreendido/a como um sujeito que não sabe e não tem conhecimento de si, não sabe quem ele/ela próprio/a é, representado/a como confuso/a. Como a repetição desse sentido do não autoconhecimento é retomada em diversos momentos, o título da série, ainda quando se refere ao sujeito trans, Quem sou eu?, enfatiza que eles/ elas (os sujeitos trans) e somente eles/elas querem responder ao questionamento, Quem sou eu?. No entanto, esse mesmo questionamento "Quem sou eu?" permite uma abertura a qualquer sujeito, para que possa se autoquestionar sobre quem é. Assim, mobilizando como perspectiva teórica a Análise de Discurso pecheutiana, pretendemos analisar os efeitos de sentidos que essa série televisiva colocou em funcionamento, acerca do tema transexualidade, a cada domingo de sua exibição.

A série Quem sou eu? foi transmitida em rede nacional durante quatro domingos consecutivos, entre os meses de março e abril, iniciando-se no dia 12 de março de 2017 e findando em 02 de abril de 2017. A cada domingo, uma temática diferente, relacionada à transexualidade, foi apresentada. Respectivamente, os títulos dos episódios foram: As escolhas de quem nasceu no corpo errado! Imagine o que você olha, não é o que você vê!; Os conflitos e descobertas de jovens que começam a descobrir o corpo; Processo de transição: intervenção cirúrgica e $\mathrm{O}$ amor e os relacionamentos no universo transgênero.

Em um segundo momento, a inquietação aconteceu diante das (não) formulações que fazem parte de demandas da comunidade trans, as quais precisam e devem ser evidenciadas. A exemplo disso, o silenciamento das questões relacionadas ao uso do nome social e o gênero (autorreconhecido pelo sujeito) que, geralmente, é atribuído a ele; o sujeito transexual e o uso destes - nome social e gênero autoidentificado - possibilitam, de certo modo, um sentimento de pertencimento ao gênero com o qual o sujeito se identifica.

No terceiro momento, a série ainda evidencia questionamentos para a esfera da saúde, uma vez que as questões ditas pertinentes à saúde do sujeito transexual (hormonização, tratamento psicológico, assistência social, exames, cirurgias, dentre outros) são apresentadas e, como se formula na série, trata-se de uma questão de saúde pública, logo, o Estado tem integral responsabilidade com esses sujeitos, o que, diversas vezes, falha, principalmente na prática de garantias de direitos.

E, em um quarto momento, é preciso discutir ainda sobre a inclusão desses sujeitos na sociedade. A inclusão é abordada pela série, porém, não se apresentam políticas públicas efetivas para que haja uma inclusão de fato, até porque essas tais políticas não existem. A série apenas apresenta os conflitos que esses sujeitos enfrentam, mas não aponta uma possível solução para esse problema social e de ordem pública, que é a inclusão dos sujeitos transexuais, sua permanência e sobrevivência na sociedade; muitos acabam por ser marginalizados e vivem às sombras, ainda que sejam cidadãos com os mesmos direitos e deveres previstos na legislação, portanto, devem/deveriam ter seus direitos respeitados, como os sujeitos não transexuais.

Assim, a história infantil de Alice no País das Maravilhas, recontada na série, traz à tona as consequências de escolhas e decisões que são tomadas ao longo da vida pelos sujeitos trans, colocando muitas situações como escolhas. Também, retoma a questão da importância de se ter conhecimentos diferentes - pensando no domínio dos mais variados campos do conhecimento - pois há um momento em que a personagem de Alice é indagada: "Mas qual caminho você quer seguir?", ao que ela responde: "Tanto faz.". Se pensarmos que em "tanto faz" qualquer caminho serve e relacionando essa formulação com a questão da transexualidade, a série coloca as questões de sexualidade e gênero como "escolhas", que tanto fazem para os sujeitos, dizeres que estão na contramão de muitas das suas lutas por uma posição legitimada e legalizada na sociedade, como um sujeito que sabe de si, que sabe quem é, e que não 
escolheu ser quem é: simplesmente o é.

Ainda, a série retoma a vida de Alice como uma menina que não se reconhece como é, e não sabe o que quer, como se ela mesma não conhecesse a si; no primeiro episódio, esse autodesconhecimento próprio da Alice é metaforizado com o suposto autodesconhecimento do sujeito transexual, como se as pessoas trans não se conhecessem ou se reconhecessem no corpo que "ocupam", como se não soubessem quem são ou não soubessem a respeito de sua orientação e desejo sexual.

Num outro momento, a série remete à história de Alice, na passagem em que ela se utiliza de poções para aumentar e diminuir o seu tamanho, conforme a necessidade que ela encontrará pela frente em sua caminhada, segundo a história infantil. De forma metafórica, evidenciase, para esse contexto de Alice, o fato da automedicação, que é algo corriqueiro, comum e dito como necessário entre os sujeitos transexuais, pois é afirmado que, somente por meio do tratamento hormonal, as mudanças físicas serão adquiridas, ou seja, é algo que fará parte da vida do sujeito transexual - o uso de medicamentos hormonais -, quando este quiser adquirir características do sexo com o qual se identifica (características que são engendradas pela sociedade, mas alicerçadas no biológico também). Isso é algo comum aos sujeitos trans, pois muitos fazem uso de medicamentos; são considerados "necessários", na medida em que o sujeito quer iniciar o processo de transição, o qual contempla mudanças corporais ou não, como é o caso daqueles que não querem fazer essas mudanças ditas necessárias.

Em outro episódio, a série evidencia a história de Alice quando ela se depara com a personagem da Rainha de Copas, que é um ser intolerante, a qual não aceita ouvir não, e quer que tudo aconteça como ela deseja, que todos estejam subordinados as suas vontades. Caso isso não aconteça, ao sujeito que a contraria, ela ordena que "cortem a cabeça". Nesse contexto, a série traz a discussão sobre a intervenção cirúrgica como "único" meio de adequar o corpo do indivíduo a sua identidade e orientação, como se o processo de transição se efetivasse de fato e somente com a cirurgia de redesignação sexual (e outras que são socialmente consideradas pertinentes aos sujeitos transexuais).
Num quarto momento, a série recupera a história infantil no viés de como Alice, após o contato com a personagem da Rainha de Copas, modifica sua forma de relacionar-se e ver os outros sujeitos e, assim, a série contextualiza a questão dos sentimentos e relacionamentos dos sujeitos transgêneros, colocando-os em um "mundo" de relacionamentos "diferentes" dos demais, por exemplo, os heterossexuais, bissexuais, etc.; logo, transexuais relacionar-se-iam apenas com transexuais, não?

A série Quem sou eu?, metaforizada pelo uso da história infantil de Alice no País das Maravilhas, ao formular um dizer a respeito do sujeito trans, como será mostrado nesse trabalho, transita, entre o discurso médico, religioso, jurídico, midiático, pois, no discurso médico, o sujeito trans é patologizado por diversos segmentos da área da saúde; já no discurso religioso, o sujeito é considerado perverso e pecaminoso, enquanto que, no jurídico, ele não é legitimado, sendo, ademais, silenciado, condenado. Assim, corroborando tudo isso, as mídias, principalmente por um funcionamento do discurso jornalístico, contribuem para a exposição desses sujeitos de uma maneira dissidente, não conhecedor de si.

Portanto, neste artigo fiz um recorte do corpus que foi analisado e discutido teoricamente em meu trabalho de dissertação. As sequências discursivas selecionadas para as análises nos permitem analisar e perceber como vários temas relacionados e que dizem e significam sobre/a transexualidade foram divulgados e postos em circulação pelo discurso jornalístico, médico, religioso e jurídico, como a união entre transexuais, questões burocráticas relacionadas à saúde, às constituições familiares, diferentes das comumente conhecidas, entre outras.

Para este trabalho trouxe uma parte da teoria trabalhada, e uma pequena parte das análises e as considerações de uma dissertação. Também foram utilizados os anos das publicações originais das obras citadas nos resumos, no entanto, parte da fundamentação teórica deste trabalho, foi realizada com edições posteriores às originais.

\section{UMA PARTE DA TEORIA}

Iniciada na França, na década de 1960, com as publicações Análise Automática do Discurso (AAD69), de Michel Pêcheux; e Langages, $\mathrm{n}^{\circ} 13$, intitulada Analyse du discours, organizada por Jean Dubois, a Análise de Discurso constitui-se em um entremeio (ORLANDI, 2015) entre o Materialismo Histórico, a Psicanálise e a Linguística.

Fundador da Escola Francesa da Análise de Discurso, Michel Pêcheux tomou para si, como objeto de estudo, o Discurso. Como pontua Orlandi (2015), o autor entendia que a ideologia era materializada e tomava forma por meio da linguagem; a linguagem era constituída pela ideologia, materializada no discurso: "Consequentemente, o discurso é o lugar em que se pode observar essa relação entre língua e ideologia, compreendendose como a língua produz sentidos por/para os sujeitos" (ORLANDI, 2015, p. 15).

Pêcheux desenvolve sua teoria baseada na relação entre ideologia (noção advinda da releitura por Althusser de Marx), linguagem (conceito deslocado de Saussure), inconsciente (na releitura por Lacan de Freud), os quais estão intrincados com o processo discursivo, no qual se efetiva a produção do discurso.

Com relação à Linguística, mais especificamente ao Estruturalismo, Pêcheux faz uma releitura de Saussure, com quem concorda com o fato de a língua ser social, mas não a considera como homogênea, e sim, em sua sistematicidade, em seu funcionamento; isto é, trata a língua no mundo, (re) considerando o sujeito que havia sido deixado de lado por Saussure. Pêcheux questiona a Linguística por negligenciar a historicidade dos sentidos. Para a Análise de Discurso, a linguagem tem uma relação necessária com a exterioridade, o que nos permite trabalhar com as condições de produção.

Durante o século XX, até o fim da década de 50, o estruturalismo de Saussure com o estudo sobre langue, por exemplo - teve grande contribuição nos estudos e pesquisas que viriam a contribuir para essa disciplina, a Análise de Discurso, que estava em processo de desenvolvimento. É a partir desse momento histórico que se começa a repensar os aspectos teóricos sobre a língua enquanto um sistema composto por signos linguísticos, discussões que pairavam entre linguistas, 
historiadores e psicanalistas; é dessa discussão, entre essas três áreas do conhecimento, que surgirá a base de estudos da Análise de Discurso Francesa. Diante disso, afirma Gadet:

Na França, a Análise de Discurso $e ́$, de imediato, concebida como um dispositivo que coloca em relação sob uma forma mais complexa do que suporia uma simples covariação, o campo da lingua (suscetivel de ser estudada pela linguística em sua forma plena) e o campo da sociedade apreendida pela história (nos termos das relações de força $e$ de dominação ideológica). Emergência temporal, também; a Análise de Discurso aparece nos anos sessenta, sob uma conjuntura dominada pelo estruturalismo ainda pouco criticado na linguística, e triunfante por ser "generalizado", isto é, exportado para as outras ciências humanas (por exemplo Lévi-Strauss ou Barthes), ou inspirador de reflexões mesmo quando não se declara explicitamente (por exemplo por Lacan, Foucault, Althusser ou Derrida). (GADET, 1997, p. 8).

Já o Marxismo, mais especificamente o Materialismo Histórico, chega até a Análise de Discurso por uma leitura de Marx, empreendida por Althusser, em Ideologia e aparelhos ideológicos do Estado (1985). O Materialismo Histórico considera que o homem faz história, mas ela não lhe é transparente. $\mathrm{O}$ que a Análise de Discurso questiona é que a própria história tem o seu real afetado pelo simbólico. Ademais, quando se fala em história na Análise de Discurso não se trata de cronologia, já que ela se relaciona a práticas e não ao tempo em si. Com efeito, Orlandi (1990, p.35) afirma que a história "se organiza tendo como parâmetro as relações de poder e de sentidos, e não a cronologia: não é o tempo cronológico que organiza a história, mas a relação com o poder (a política)".

A influência de Althusser nas teorias de Pêcheux teve início ainda nos anos 1960, quando Pêcheux participou de um seminário ministrado por Althusser na Escola Normal Superior (Paris França). Durante esse seminário, Pêcheux percebe que está em meio ao embate das reproduções pensadas pela elite e as releituras do marxismo, o materialismo histórico da luta de classes, feitas por Althusser. Diante disso, Pêcheux assumiu o pseudônimo de Thomas Herbert e passou a produzir alguns escritos. Como afirma Henry (1997):

De fato, os conceitos e as noçõeschaves dos textos assinados Thomas Herbert, que fazem explicitamente referência ao 'materialismo histórico' e à 'psicanálise', estão quase que completamente ausentes do livro de Pêcheux sobre a análise automática do discurso. (HENRY, 1997, p. 13-14).

Mas era a primeira publicação de Pêcheux, entre 1960 e 1970, texto no qual ele desejou suscitar a discussão de uma possível articulação entre os campos de estudo do materialismo histórico, da psicanálise e da linguística.

Nas publicações posteriores, com o pseudônimo de Herbert, o materialismo histórico estava presente nos textos do teórico, momento em que o autor também reavivava as críticas ao estruturalismo de Saussure: "o que interessava a Pêcheux no estruturalismo eram aspectos que supunham uma atitude não-reducionista no que se refere à linguagem" (HENRY,1997, p. 14), distanciando-se da noção de língua enquanto forma abstrata. A Análise de Discurso, porém, não deixava de considerar as questões articuladas entre a linguagem e os processos discursivos, pensando naquilo que se referia à língua e ao discurso como prática política:

Segundo Althusser, e tendo como referênciaaideologiaquePêcheux introduz o sujeito enquanto efeito ideológico elementar. É enquanto sujeito que qualquer pessoa é "interpelada" a ocupar um lugar no sistema de produção. Em um texto publicado mais tarde, ao qual Pêcheux refere-se com frequência, Althusser escreve: "Como todas as evidências, incluindo aquela segundo a qual uma palavra 'designa uma coisa' ou 'possuía uma significação', ou seja, incluído a transparência $d a$ evidência $d a$ linguagem, esta evidência de que eu e você somos sujeitos - e que este fato não constitui nenhum problema - é um efeito ideológico, o efeito elementar. (HENRY, 1997, p. 30).

Pensando nesse sujeito que é afetado pela ideologia, mas que falha - e é nessa falha que o inconsciente se expressa na/ pela linguagem, com relação à Psicanálise -, a Análise de Discurso concorda com o deslocamento da noção de homem para a de sujeito (afetado pelo inconsciente), mas trabalha a ideologia considerando-a como materialmente relacionada ao inconsciente, sem que este seja tomado por ela. Segundo Orlandi (2015, p. 20), isso implica em "dizer que o sujeito discursivo funciona pelo inconsciente e pela ideologia".

Ao falar acerca da Análise de Discurso, Pêcheux (2015, p. 288) afirma que:

\begin{abstract}
No contexto filosófico e político evocado acima, o projeto da análise de discurso marca uma ruptura com esta problemática psicossocial pela qual o triplo registro da história, da língua $e$ do inconsciente permanece literalmente recalcado. As teorias e métodos desenvolvidos em análise de discurso não pararam de se confrontar com essa situação de triple recalque, com a esperança (que se poderá julgar ingenuamente pretensiosa) de contribuir para desfazer esse nó.
\end{abstract}

A Análise de Discurso está entremeada por essas três áreas de conhecimento - linguística, materialismo histórico e psicanálise - e, por se tratar de uma disciplina de interpretação, procura observar o que é e não é observável no discurso, levando em consideração seu "espaço" de produção e circulação, como é o caso dos "espaços discursivos não estabilizados logicamente, derivando dos domínios filosófico, sócio-histórico, político ou estético, e logo também o dos múltiplos registros do cotidiano não estabilizados" (PÊCHEUX, 2015, p. 292).

Em 1975, quando a Análise de Discurso está mais sustentada teoricamente, pois já estão articuladas as áreas de entremeio da linguística, do materialismo histórico e da psicanálise, Pêcheux busca com base em um processo de "desconstrução objetivista e subjetivista” (MALDIDIER, 2003, p. 
38), compreender a interligação entre a ideologia, o discurso e a subjetividade:

\section{[...] o campo teórico, o "quadro epistemológico" do empreendimento que articula três regiões de conhecimento análises. \\ UM POUCO DAS ANÁLISES - OS DISCURSOS} cientificas: - $O$ materialismo histórico como teoria das formações sociais e suas transformações, ai compreendida a teoria das ideologias; - A linguística como teoria ao mesmo tempo dos mecanismos sintáticos e dos processos de enunciação: A teoria do discurso como teoria da determinação dos processos semânticos. Intervém uma quarta referência de "uma teoria da subjetividade (de natureza psicanalitica)". É apontado o que vai estar no centro da proposta: a questão da leitura, na sua ligação com a do sujeito. (MALDIDIER, 2003, p.38).

Orlandi (2015, p. 13) salienta, porém, que a AD tem seu método e seu objeto próprio, que se relacionam com a linguística, $o$ materialismo histórico e a psicanálise, todavia, que não se confundem com eles. Ainda de acordo com a autora (2015, p. 14), a $\mathrm{AD}$ constitui-se como uma "disciplina de entremeio", que se formula na contradição desses três campos do saber:

Podemos, isso sim, dizer que a análise de discurso pressupõe a psicanálise, a lingüística e o marxismo. E os pressupõe na medida em que se constitui da relação de três regiões científicas: a da teoria da ideologia, a da teoria da sintaxe e da enunciação, e a teoria do discurso como determinação histórica dos processos de significação. Tudo isso atravessado por uma teoria psicanalitica do sujeito. É este o contexto teórico da análise de discurso. São essas as condições históricas do aparecimento da análise do discurso (ORLANDI, 2015, p. 13).

Após essa breve apresentação da base teórica da Análise de Discurso, passaremos a discorrer sobre as conclusões acerca dos sujeitos trans possíveis, com as nossas

Nesta sessão discuti como os efeitos de sentidos são produzidos em cada sequência discursiva, analisando como cada tipo de discurso - médico, religioso, jurídico e midiático - produz sentidos por/ para os sujeitos transexuais.

Aqui os subtítulos seguem um contexto de análise, indicando a ocorrência de determinados discursos para dizerem sobre transexuais, portanto, os subtítulos seguem orientando o leitor para uma análise de acordo com o discurso indicado no título das subsessões

\section{Discurso Médico}

O discurso médico aparece na série nos dizeres dos diferentes profissionais da saúde ao enunciarem sobre os sujeitos trans. Na primeira SD a ser analisada, é retomado o dizer de Alexandre Saadeh, que, no contexto em que a série está acontecendo, explica sobre a formação de uma criança desde o momento de sua concepção, passando pela formação de áreas específicas relacionadas à sexualidade, como a genitália e o cérebro, ao justificar o que houve com Melissa, menina transexual, que é a principal personagem do primeiro episódio.

SD Médico Alexandre Saadeh: no embrião humano né, a, a genitália se forma por volta da décima semana, enquanto isso, $\boldsymbol{o}$ cérebro está em desenvolvimento, mas, por volta da vigésima semana, se define a área que dá a identidade de gênero que a gente chama. (grifos da autora)

No início da $\mathrm{SD}$, o referido médico marca uma distinção entre o ser humano e o restante dos animais, afirmando e ao mesmo tempo duvidando, o que fica perceptível com o uso do advérbio "né" - uma marcação que nos remete a pensar que a transexualidade, que é o tema em discussão na série, não é percebida ou não ocorre em outros animais, que não os seres humanos.

Ainda, na mesma SD, o médico relaciona o órgão sexual "a genitália" com o cérebro, sugerindo o complemento de um em função do outro, ao dizer que a genitália se "forma", portanto, tem um modelo que é biologicamente estabilizado - vagina, pênis, ou ambos, como é o caso do intersexo - não podendo ser outros, mas que esses modelos não necessariamente correspondem à função dessa genitália, que é esperada pela sociedade, mas sim, sobre como essa função é atividade do cérebro, quando a parte responsável se desenvolve. Isso comprova o fato de que a função sexual do sujeito está condicionada ao que o seu sistema nervoso, controlado também pelo cérebro, indicar, portanto, não está associado àquilo que a sociedade esperará, de acordo com as suas normas impostas, que são alicerçadas em dizeres religiosos, por exemplo, o matrimônio na Igreja Católica - que é somente permitido e aceito a partir da união de pessoas de sexos diferentes, ou seja, um homem e uma mulher.

O médico ainda diz sobre a "área que dá a identidade de gênero", ou seja, novamente, sobre o seu discurso, ele afirma que a identificação com o gênero é algo dado e não construído socioculturalmente. Porém, como é mostrado na discussão anterior, o gênero com que o sujeito irá se identificar na sociedade é algo construído por essa mesma sociedade e pelos sujeitos no contato com outros sujeitos. Portanto, identificar-se com um gênero ou outro, ou ainda com nenhum, é algo que cabe somente ao sujeito como processo de identificação. Todavia, para o discurso médico, essa identificação efetiva-se em uma área "dada", no momento de gestação que, como afirma o médico, é por volta da vigésima semana gestacional. Diante disso, ressalta Butler (2003, p. 24-25):

A hipótese de um sistema binário dos gêneros encerra implicitamente a crença numa relação mimética entre gênero e sexo, na qual o gênero reflete o sexo ou é por ele restrito. Quando o status construído do gênero é teorizado como radicalmente independente do sexo, o próprio gênero 
se torna um artifício flutuante, com a consequência de que homem e masculino podem, com igual facilidade, significar tanto um corpo feminino como um masculino, e mulher e feminino, tanto um corpo masculino como um feminino.

Essa afirmação da autora nos ajuda a entender a ausência da relação dita pela sociedade - existente, entre sexo e gênero, uma vez que o sexo é de ordem biológica e o gênero é da ordem do social. Nas palavras de Butler (2003, p. 27), retomando Beauvoir: "Beauvoir diz claramente que a gente 'se torna' mulher, mas sempre sobre uma compulsão cultural a fazê-lo. E tal compulsão claramente não vem do "sexo".

\section{Discurso Religioso}

Na série Quem sou eu?, alguns dizeres, inscritos no discurso religioso, chamam a atenção; como eles produzem sentidos sobre/para os sujeitos trans, houve a intenção de analisá-los. É o caso quando o programa retoma a história do personagem, no segundo episódio, sobre Bernardo, rapaz transexual. Nesse contexto, a narradora da série, Renata Ceribelli, conversa com Bernardo e sua mãe sobre a rotina do rapaz e a sua vivência enquanto homem transexual que é, ao que o jovem responde:

SD Bernardo homem trans: o bullying eu sei que ele nunca vai acabar, porque eu sou quem eu sou, e tem pessoas que se sentem ofendidas, porque a diferença sempre traz discórdia, né? (grifos da autora)

Em seu dizer, Bernardo se utiliza de um substantivo feminino "ofensa" para dizer como as pessoas se sentem em relação ao que ele é, um homem trans: "pessoas que se sentem ofendidas". O adjetivo "ofendidas" derivado do substantivo ofensa, utilizado por Bernardo, retoma uma memória de injúria, desacato, ação de violar uma norma, uma regra, um dogma. Tal termo é muito utilizado no discurso religioso; dessa forma, ao dizer sobre um sentimento de ofensa, pois é assim que as pessoas se sentem diante dos sujeitos trans, o próprio Bernardo retoma esse dizer religioso, associado ao sujeito trans, visto que, por exemplo, é algo/alguém fora das normas, regras e preceitos da religiosidade.
Bernardo usa o substantivo feminino "discórdia", que é outro termo utilizado no discurso religioso, para falar da desavença, a falta de entendimento, o desacordo, a luta, a divergência, entre outros significantes, com sentidos de desunião, de reprovação, o que não é considerado bom; ele completa seu enunciado da seguinte maneira "a diferença sempre traz discórdia, né?", ou seja, os sujeitos trans são ditos como diferentes do que a sociedade impõe como certo/adequado/ correto e Bernardo reafirma essa memória de que os sujeitos trans, por serem diferentes, é que causam tantas coisas ruins relacionadas à discórdia, ao invés de mostrar que as pessoas precisam entender quem são os trans. Porém, ao afirmar que o diferente - e aqui substituímos pelo trans, “o trans sempre traz discórdia né?" -, Bernardo reafirma a ideologia sobre o trans ser algo ruim, propósito de desavenças e mal-entendidos; ademais, deixa o questionamento para o telespectador, por meio do uso do advérbio "né", que serve como interrogação e fica como reflexão para o sujeito.

A segregação do sujeito transexual na sociedade começa com o tipo de uniforme, que é diferente para meninos e meninas, além das filas:

Quando de fato, a diferença é anterior, é constitutiva dessa suposta igualdade. Portanto, não se trata de "saber conviver", mas ter claro que a sociedade se organiza e se estrutura na e pela diferença. Se tivermos esta premissa clara, talvez possamos inverter a lógica: não se trata de identificar o estranho como diferente, mas de pensar que estranho é ser igual e quanta violência é cometida para se produzir o hegemônico transfigurado em uma igualdade natural. (BENTO, 2008, p. 169).

E, é por isso que as discussões sobre as diferenças são tão importantes, de maneira que a unificação dos pequenos grupos (movimentos sociais: de mulheres, negros, homossexuais, intersexos, drags, crossdresser, indígenas, etc.) marginalizados veem se transformando em movimentos dominantes, porque todos são diferentes e poucos são os que se dizem iguais ou normais, iguais, ou legais.

\section{Discurso Jurídico}

O discurso legal, aquele inscrito no âmbito do jurídico, tem como premissa garantir a ordem social; sua aplicabilidade se estende de forma igual a todos os cidadãos. Isso é o que deveria acontecer, pois cada caso tem uma especificidade e a aplicabilidade da lei não é a mesma para todos os sujeitos ou, ainda, quando as leis não contemplam as especificidades desses sujeitos, como é o caso dos trans.

Então, cabe ao Estado garantir direitos e deveres aos transgêneros, mas, como observaremos na $\mathrm{SD}$ a seguir, isso não acontece. Segundo Cavalieri Filho (2015, p. 30): "as atividades humanas assumem forma múltiplas, econômicas ou não, mas todas elas podem ser reduzidas a dois tipos: atividades de cooperação e atividades de concorrência". Essa "cooperação" e também a "concorrência" está demarcada no discurso jurídico, quando aplica a lei para o sujeito, entretanto, para que forma e para qual sujeito; assim, tem-se a concorrência.

Na próxima SD, temos a fala de Renata Ceribelli que, durante o segundo episódio, o qual discutiu questões sobre a medicação e a saúde da população transgênera, coloca em evidência a falha do Estado por meio do jurídico. Observemos:

SD Renata Ceribelli: é ai que
muitos trans optam pela perigosa
automedicação. Desde 2008, é
possível fazer esse tratamento
peloSUS, em 9 centros pelo Brasil,
mas é preciso ter mais de 18 anos
e passar por acompanhamento
psicológico. Você diria que entre
os transexuais hoje, no Brasil,
qual a porcentagem que acaba se
automedicando por falta de um
atendimento na rede pública?
(grifos da autora)

Na SD acima, Renata está em um contexto da série que fala sobre a medicação e as cirurgias no processo de transição que o sujeito transexual, segundo ela, passa. No início da $\mathrm{SD}$, ela explicita que os sujeitos trans, em sua maioria, "optam pela perigosa automedicação" e, ao final da $\mathrm{SD}$, se contradiz ao dizer questionar um médico sobre a porcentagem de pessoas trans que vão "se medicando por falta de um atendimento na rede pública". Em um primeiro momento, a locutora afirma que 
o sujeito transexual é quem opta, quem escolhe pela automedicação, porém, depois, ela deixa evidente que o Estado, representado aqui pelo SUS, que deveria garantir esse atendimento, não comporta ou não fornece esse atendimento.

Em um outro momento, na mesma SD, ela aponta para a legalização do tratamento pelo serviço de saúde pública: "desde 2008 é possível fazer esse tratamento pelo SUS", ou seja, o Sistema Único de Saúde, por lei, deve ofertar esse tipo de tratamento voltado para a transexualidade, no entanto, são poucos os centros de saúde que disponibilizam essa especialidade. Esse é um exemplo de como o Estado garante o direito na lei, torna isso legal por meio do jurídico, mas não oferece condições para que se cumpra. Assim esse sujeito, parece ser um indivíduo que não existe, sem direito, sem identidade.

O sujeito transexual é visto pela sociedade como aquele que não possui uma identidade própria, mas que se apropria das outras identidades, como se fosse um sujeito não verdadeiro:

Muito mais do que um corpo de exclusão (não é homem, não é mulher), o sujeito transexual apresenta um corpo de transição entre um gênero e outro. Nessa transição, que foge à organização estabilizada da norma, da rigidez da estrutura, configura-se um corpo ambivalente, (in)capaz de ser significado como legítimo nessa sociedade, configurandose como um corpo (im)possivel, cujos sentidos significam justamente no entre-lugar do discurso. (CASSANA, 2018, p.21).

Logo, esses sujeitos, os transexuais, são ditos como sujeitos sem identidade. No entanto, como ressalta Cassana (2018), possuem, sim, uma identidade, que é a sua própria constituição construída na sua vivência. Nos termos da autora, "mediante uma marca, o sujeito transexual rememora quem um dia foi, mesmo que na atualidade seu corpo esteja identificado com outro gênero" (CASSANA, 2018, p.21), ou seja, a identificação com o gênero, que antes era oposto e agora identifica o sujeito transexual, não apaga quem é esse sujeito, como foi constituído, muito menos seu processo sócio-histórico-ideológico de assujeitamento.

\section{Discurso Midiático}

O discurso midiático foi pensado neste trabalho, uma vez que o objeto de análise é a série Quem sou eu?, a qual foi televisionada. Logo, tal discurso coloca em circulação os diferentes e mais variados sentidos, porém, não é possível saber como os telespectadores da série atribuíram significados aos dizeres que até eles chegaram pela televisão.

Para pensarmos em algumas possibilidades e alguns sentidos ideologicamente estabilizados sobre os sujeitos trans, trouxe uma SD para compreender melhor o funcionamento do discurso da mídia na série. Isso pode ser observado na SD a seguir:

SD Renata Ceribelli: gênero só existem dois, o masculino $e$ o feminino; transgênero é uma pessoa que não se identifica com o gênero de nascença, por exemplo; uma pessoa que nasce homem, mas não se sente do gênero masculino, ou, que nasce mulher e não se identifica com $o$ gênero feminino. (grifos da autora)

A SD acima faz parte do contexto do início do primeiro episódio da série, no qual Renata Ceribelli inicia a SD afirmando o dizer de que só existem dois gêneros "gênero só existem dois, o masculino e o feminino"; depois, ela termina a SD com a explicação sobre a transexualidade, mas, em nenhum momento da SD, ela fala sobre outra possibilidade de ser que não seja a de masculino ou de feminino, invisibilizando as pessoas não-binárias, as quais não se identificam com nenhum gênero.

Ela ainda afirma que "transgênero é uma pessoa que não se identifica com o gênero de nascença"; nessa afirmação, está dizendo que a pessoa já nasce com um gênero, novamente, marcando que existe um gênero, desconsiderando as outras possibilidades, e também faz toda a explicação sobre a transexualidade, baseada na binaridade masculino/ feminino, homem/mulher, reafirmando dizeres acerca dos gêneros que contemplam apenas dois como possibilidade de serem, masculino ou feminino.
Aliás, a grande maioria dos homens não assume explicitamente essa pretensão. Eles não colocam a mulher como uma inferior; estão hoje demasiado compenetrados do ideal democrático para não reconhecer todos os seres humanos como iguais. No seio da familia, a mulher apresentase à criança e ao jovem revestida da mesma dignidade social dos adultos masculinos; mais tarde ele sente no desejo e no amor a resistência, a independência, da mulher desejada e amada; casado, ele respeita na mulher a esposa, a mãe, e na experiência concreta da vida conjugai ela se afirma em face dele como uma liberdade. o homem pode, pois, persuadirse de que não existe mais hierarquia social entre os sexos e de que, grosso modo, através das diferenças, a mulher é sua igual. Como observa, entretanto, algumas inferioridades - das quais a mais importante é a incapacidade profissional - ele as atribui à natureza. Quando tem para com a mulher uma atitude de colaboração e benevolência, ele tematiza o princípio da igualdade abstrata; e a desigualdade concreta que verifica, não a põe. (grifos da autora)

Endossando o que disse a autora na citação, não há por parte do Estado uma mobilização real para garantir e democratizar os direitos das pessoas transexuais, pois ainda temos o homem branco heteronormativo ocupando as cadeiras de poder na sociedade, pautado na distinção biológica de sexo, feminino/ masculino, mulher/homem. A exposição dos sujeitos transexuais na mídia atualmente e infelizmente, tem sido nas manchetes de jornais ou noticiários, quando anunciam crimes de homicídio, feminicídio nos quais os sujeitos trans são as vítimas, vítimas de transfeminicídio.

Este trabalho me permitiu uma série de reflexões sobre a transexualidade e os sujeitos transexuais na sociedade, principalmente por compreender como os discursos funcionam produzindo sentidos sobre, para e por estes sujeitos, como escrevo na próxima sessão.

Conforme Beauvoir (1949, p. 20): 


\section{DIZERES FINAIS}

A série Quem sou eu? retratou diversos dizeres sobre a transexualidade e os sujeitos trans, a qual, na medida do possível de ser dito pela/na língua/gem, fez circular os diferentes sentidos sobre o tema principal da série, a transexualidade.

Existe uma resistência do Estado responsável pela ordem legal na sociedade - em legalizar as petições que surgem dos grupos, comunidades ou instituições correlacionados às causas dos sujeitos trans e dos LGBTQI+; isso se justifica pelo fato de que, ao serem reconhecidos pela lei como sujeitos de direitos, eles poderão ocupar os mesmos lugares que os cidadãos não trans e, então, esse sujeito, que está à margem da sociedade, passaria a ser um sujeito de direito como os demais. No entanto, a sociedade e o Estado funcionam como Aparelhos Ideológicos Repressivos sobre o sujeito, de forma que concedem os direitos, mas não as condições para que exerçam e façam uso desses direitos, limitando-os em todos os segmentos.

O trans é um sujeito que não tem lugar na esfera religiosa, pois não há conhecimento de alguma religião que o tome como ele/ ela é; as religiões podem até aceitar o sujeito trans com o intuito de que se regenere, mude, enfim, enquadre-se no binarismo homem e mulher, pregado pela grande maioria das religiões, visto que entendem esse sujeito como pecador e desobediente aos ensinamentos de Deus/ deuses.

Esse binarismo, citado anteriormente, tem uma base biológica do que é um corpo feminino e um corpo masculino, ideologia responsável pelo ideal de corpo masculino com pênis e sem seios e do feminino com vagina e com seios, características principais a serem modificadas quando se fala em sujeitos trans, ideia propagada pelos próprios sujeitos transexuais também.

Os sujeitos trans, depois de todo o processo de aceitação de si mesmos, ainda são condicionados pela sociedade a se encaixar nesse padrão, apresentado anteriormente, do ser homem e do ser mulher, ou seja, todos acabamos nos inscrevendo em uma ideologia do corpo e do gênero, que é ditada pela sociedade e interdita por vários outros meios, como é o caso de sujeitos que se submetem aos tratamentos considerados para os sujeitos transexuais.

A demanda dos tratamentos transexualizadores pelo SUS (Sistema Único de Saúde) sempre foi muito grande e, quando disponibilizado, foi restrito a alguns centros, o que ocasionou as grandes filas de espera. Essas filas justificam tal demanda de atendimento público de saúde para a população trans, que tardou em acontecer, mas, antes de tudo, as filas, ditas enormes representam a quantidade de pessoas que fazem parte da sociedade e que não tinham seus direitos contemplados pela saúde pública. Esses sujeitos pagam seus impostos, assim como todos os outros, pois nenhum trans é livre de impostos por ser trans, então, não existe motivo para que não tenham assistência médica gratuita pelo fato de serem trans.

O discurso da medicina, em geral, entende o sujeito trans como doente e, por isso, talvez, tenha julgado necessário o acompanhamento/tratamento até então desses sujeitos, para que "alguém", um outro, diga e ateste, ou ainda afirme sobre seu estado de ser trans. A transexualidade deixou de ser considerada uma doença, relacionada a um transtorno sobre a sexualidade, é possível que, nos próximos anos, a transexualidade ressignifique esse sentido de doença mental, de modo que alguns profissionais parem de propor a cura para algo que não é doença.

É importante essa visibilidade dos sujeitos trans, uma vez que tais sujeitos são invisibilizados, na maioria das vezes, também no mercado de trabalho, quando conseguem adentrar o mercado de trabalho formal. A maioria dos sujeitos transexuais, principalmente as mulheres trans, vivem da prostituição. Há algumas exceções, mas que ocupam cargos de auxiliares como recepcionista, auxiliar administrativo, cozinheiro, diarista, professor (a), não cargos com prestígio social mais elevado, como médico, advogado, engenheiro, arquiteto, etc.

Essa questão legal, da falha do jurídico, reflete-se bem quando se trata de crime de transfobia, pois todos os crimes com esse perfil são noticiados como homicídios, como se não tivessem uma motivação única, que é o fato da vítima ser um sujeito trans.
Contamos hoje com muitas produções científicas de pessoas travestis e transexuais, no entanto, ainda somos ditas, por pessoas cisgêneras. Este trabalho, por exemplo, é uma produção de uma mulher transexual, que pesquisa e produz conhecimento acerca dessa comunidade e que almeja a propagação de trabalhos escritos por mulheres transexuais e travestis, pois nós somos capazes também de produzir conhecimentos, tanto que trouxe uma parte bem concisa da minha pesquisa de mestrado neste artigo.

Há muito que se aprender sobre as diferentes formas de ser e exercer a sexualidade e é nesses ditos e não-ditos que os sujeitos trans vão legitimando a sua existência na sociedade; aquilo que parecia ser um sujeito impossível toma forma, corpo e voz, transformando aquilo que era impossível, possível com base na língua, na linguagem, nos dizeres, nos sentidos, na existência e na resistência.

\section{REFERENNCIAS}

BENTO, Berenice Alves de Melo. O que é transexualidade?. São Paulo. Editora Brasiliense, 2008.

BEAUVOIR, Simone de. O Segundo Sexo. v. I e II. [1949]. Trad. Sérgio Milliet. 4a Ed. São Paulo: Difusão europeia do livro, 1970.

BUTLER, Judith P. Problemas de gênero: feminismo e subversão da identidade. Rio de Janeiro: Civilização Brasileira, 2003

CASSANA, Mônica Ferreira. Corpo e(m) discurso: ressignificando a transexualidade. 1a ed. Curitiba: Editora Appris, 2018.

CAVALIERI FILHO, Sergio. Programa de Sociologia Jurídica. 14a ed. Rio de Janeiro: Editora Forense, 2015.

GADET, Françoise; HAK, Tony. [1969].

Por uma análise automática do discurso. Uma Introdução à Obra de Michel Pêcheux. São Paulo: Editora da Unicamp, 1997.

MALDIDIER, Denise. A inquietação do discurso - (Re) ler Michel Pêcheux hoje. Trad. Eni P. Orlandi. Campinas, SP: Editora Pontes, 2003. 
ORLANDI, Eni Puccinelli. Análise de Discurso: princípios e procedimentos. 12a ed. Campinas, SP: Pontes Editores, 2015.

Discurso e Texto: formulação e circulação dos sentidos. 4a ed. Campinas- SP: Pontes Editores, 2012. - Palavra, fé e poder. (Org).

Eni Puccinelli Orlandi. Campinas - SP.
Editora Pontes, 1987

As formas do silêncio: no

movimento dos sentidos. 6a ed.

Campinas - SP, Editora da UNICAMP, 2007

PÊCHEUX, Michel. Análise de Discurso: Michel Pêcheux Textos Selecionados:

Eni Puccinelli Orlandi. 4a ed.

Campinas, SP: Pontes Editores, 2015.
Semântica e Discurso: uma crítica à afirmação do óbvio. [1975]. $2^{a}$ ed. Campinas - SP: Editora da Unicamp, 1995.

O Discurso: estrutura ou acontecimento. Trad: Eni Puccinelli Orlandi. 5a ed. Campinas - SP: Pontes editores, 2008.

\section{Recebido em 14 Jan 2019 | Aprovado em 07 Jun 2019}

Jaqueline Angelo dos Santos DENARDIN

Doutoranda do Programa de Pós-Graduação em Estudos da Linguagem do Instituto de Linguagens da Universidade Federal do Mato Grosso - Campus Cuiabá. E-mail: jaquelinedenardin@hotmail.com. 